\title{
Terminologia de parentesco e casamento djeoromitxi: um caso ngawbe na Amazônia?
}

\section{Nicole Soares-Pinto}

\section{(2) OpenEdition}

1 Journals

Edição electrónica

URL: http://journals.openedition.org/aa/1744

DOI: $10.4000 /$ aa. 1744

ISSN: 2357-738X

Editora

Programa de Pós-Graduação em Antropologia Social (UnB)

\section{Edição impressa}

Data de publição: 1 julho 2016

Paginação: 123-151

ISSN: 0102-4302

\section{Refêrencia eletrónica}

Nicole Soares-Pinto, «Terminologia de parentesco e casamento djeoromitxi: um caso ngawbe na

Amazônia?», Anuário Antropológico [Online], v.41 n.1 | 2016, posto online no dia 05 junho 2018, consultado o 28 abril 2021. URL: http://journals.openedition.org/aa/1744 ; DOI: https://doi.org/ 10.4000/aa. 1744

\section{(c) (7) (9)}

Anuário Antropológico is licensed under a Creative Commons Atribuição-Uso Não-Comercial-Proibição de realização de Obras Derivadas 4.0 International. 


\title{
Terminologia de parentesco e casamento djeoromitxi: um caso ngawbe na Amazônia?'
}

\author{
Nicole Soares-Pinto \\ Museu Nacional/UFRJ
}

Este artigo apresenta um modelo do sistema de parentesco djeoromitxi, povo de língua Macro-Gê (Ribeiro \& Van Der Voort, 2010), habitante do sudoeste amazônico (Terra Indígena Rio Guaporé/Rondônia). Os Djeoromtxi, hoje, são cerca de 200 pessoas e compóem o que Galvão (1960) denominou a "área cultural do Guaporé" e o que Maldi (1991) caracterizou como o "Complexo Cultural do Marico". A descriçẫo do sistema de parentesco djeoromitxi incluirá a terminologia vocativa para os parentes, que será relacionada a um modelo de cruzamento e aliança, na medida em que essa terminologia codifica os cônjuges que são preferenciais (aos quais se aplica o termo wirá), mas não correspondem aos primos cruzados. Veremos que tipo de cruzamento é concernente ao modelo djeoromitxi de parentesco.

No intuito de esboçar um sistema de alianças em que os Djeoromitxi estão incluídos, chamarei "entes trocadores" os povos indígenas (grupos de pertencimento patrifiliativos) que configuram esse campo social: os Tupari, Makurap e Wajuru, de língua Tupi-Tupari; os Arikapo, de língua Macro-Gê; os Aruá, de língua TupiMondé; os Kanoê, de língua Kanoê; e os Kujubim, de língua Txapacura. Para fins desta análise, a distinção segmentar interna a tais povos será ignorada. Isso tem seus motivos: ainda que se possa observar casamentos no interior desses povos, caso em que a distinção segmentar é importante, meus interlocutores relacionam esse tipo de aliança (casamentos linguisticamente endogâmicos) como aqueles mais amplamente ocorridos no "passado da maloca". Antes de os não indígenas aparecerem, cada aldeia congregava várias malocas, e cada maloca pertencia a um subgrupo de mesma língua que aqueles presentes em outras malocas da mesma aldeia. Os casamentos ocorriam no interior da aldeia, entre malocas, isto é, entre subgrupos de um mesmo povo ou língua.

Hoje, com as sucessivas mudanças no padrão residencial que se deu na dissolução ou, como dizem, "saída da maloca", a partir da segunda metade do século XX, há um novo tipo de aliança, desta vez entre os povos (ou entre aldeias, se fôssemos aplicar o padrão antigo, que, dessa perspectiva, ainda se mostra operante), configurando um padrão de exogamia linguística muito mais observável. Assim, 
as aldeias atuais reúnem diversos povos, e suas casas são "misturadas", de cônjuges de povos e línguas distintas, reunidos em torno de um chefe de família extensa, normalmente atendendo a um padrão virilocal. Os casamentos no interior de um grupo linguístico ocorrem num número muito menor que aquele entre pessoas de línguas distintas. ${ }^{2}$

É nesta última escala, da exogamia linguística, que as análises aqui apresentadas visam se inscrever. Ademais, ver-se-á que a distinção entre os povos e as patrilinhas que os compõem internamente não é pertinente para os argumentos aqui apresentados e, nesse sentido, a definição dos "entes trocadores" pode oscilar entre um e outro sem prejuízo para a leitura de seu sistema de aliança. Quando não for esse o caso, notas serão adicionadas à descrição. ${ }^{3}$

\section{Terminologia djeoromitxi}

Consideremos agora as principais equaçóes da terminologia vocativa presentes no sistema de parentesco djeoromitxi. Para a leitura da tabela, a marcaçáo obedece às denominaçóes em língua inglesa: (m) /male/ Ego masculino e (f) / female/ Ego feminino; /e/ (elder) mais velho e /y/ (younger) mais novo. Os kintypes marcados por asterisco $\left(^{*}\right)$ recebem um sufixo diminutivo, /-kabu/.

Devo registrar primeiramente que, até onde pude saber, os termos de referência em língua djeoromitxi são produzidos pelos prefixos de possessáo adicionados ao termo vocativo, que pode ser consultado na tabela abaixo. Por conta de somente serem adicionados os prefixos de possessão, no caso dos termos de referência, é que optei por apresentar a terminologia vocativa. Há somente uma excessão: o termo de referência para $M$ parece diferir desse esquema, pois é construído com os prefixos de possessão mais o termo dji, enquanto, no caso vocativo, 'M' é chamada por tätxi. ${ }^{4}$ Assim, no caso dos termos vocativos, temos djevetxia dji, "minha mãe"; a dji, "mãe dele"; $i$ dji, "tua mãe". Ademais, os termos de afinidade são específicos e, para $\mathrm{MH}$ e $\mathrm{FH}$, temos termos descritivos: tãtitarô e hotxitädi, respectivamente. 
Tabela 1 - Termos de parentesco em Djeoromitxi

\begin{tabular}{|c|c|c|}
\hline & Termo & Kintypes principais \\
\hline 1 & Hotõ & FF; MF; \\
\hline 2 & Kuré & MM; FM; \\
\hline 3 & Hotxi & $\mathrm{F} ; \mathrm{FB}^{*}, \mathrm{FZS}^{*}$ \\
\hline 4 & Tätxi & M; MZ; FBW; MMZD \\
\hline 5 & Téti & MB; MMZS; \\
\hline 6 & Dikon & FZ; MBW; (f)FZD*; (m)FZD* \\
\hline 7 & Neé & (m)eB; (m)FBeS; (m)MZeS; \\
\hline 8 & Psiré & (m)yB; (m)FByS; (m)MzyS; \\
\hline 9 & Veé & (m)eZ; (m)FBeD; (m)MZeD; \\
\hline 10 & Nií & (f)yB; (f)FByS; (f)MzyS; \\
\hline 11 & Rain & (f)eB; (f)FBeS; (f)MZeS; \\
\hline 12 & Pako & (m)yz; (m)FByD; (m)MZyD; \\
\hline 13 & Hohé & (f)eZ; (f)FBeD; (f)MZeD; \\
\hline 14 & Taã & (f)yz; (f)FByD; (f)MZyD; \\
\hline 15 & Itxi & (m)D; (m)BD; (m)MBD, (m)FBSD; (m) MZSD; \\
\hline 16 & Ukü & (m)S; (m)BS; (m)MBS; (m)FBSS; (m)MZSS; \\
\hline 17 & Tã & (f)Ch; (f)ZCh; (f)HBCh; (f)MZDCh; (f)FBDCh; \\
\hline 18 & Teé & $(\mathrm{m}) \mathrm{ZCh} ;(\mathrm{m}) \mathrm{MZDCh} ;$ \\
\hline 19 & Foõ & (f)BCh; (f) MBCh; (f) MZSCh; (f) FBSCh; (f) HZCh; \\
\hline \multirow[t]{2}{*}{20} & Fõ & $\mathrm{ChCh}$ \\
\hline & Termos de afinidade & \\
\hline 21 & Tarõ & $\mathrm{H} ; \mathrm{HB}$; \\
\hline 22 & Tãdi & W; WZ; \\
\hline 23 & Rainõ & $\mathrm{DH} ; \mathrm{ZH} ; \mathrm{HB} ; \mathrm{FZH} ;$ \\
\hline 24 & Rotõtxi & WF; WFB; HF;HFB; HMB; \\
\hline 25 & Ditché & SW; WM; WMZ; BW;WBD;WZD;HZD;HM;HZ; \\
\hline \multirow[t]{2}{*}{26} & Wirá & FZChCh; MBChCh; \\
\hline & & FMBCh; FFZCh; MFZCh; MMBCh; \\
\hline
\end{tabular}

Fonte: Soares-Pinto, 2014: 126 
Figura 1 - Quadro terminológico para Ego masculino (parentes consanguíneos) ${ }^{6}$

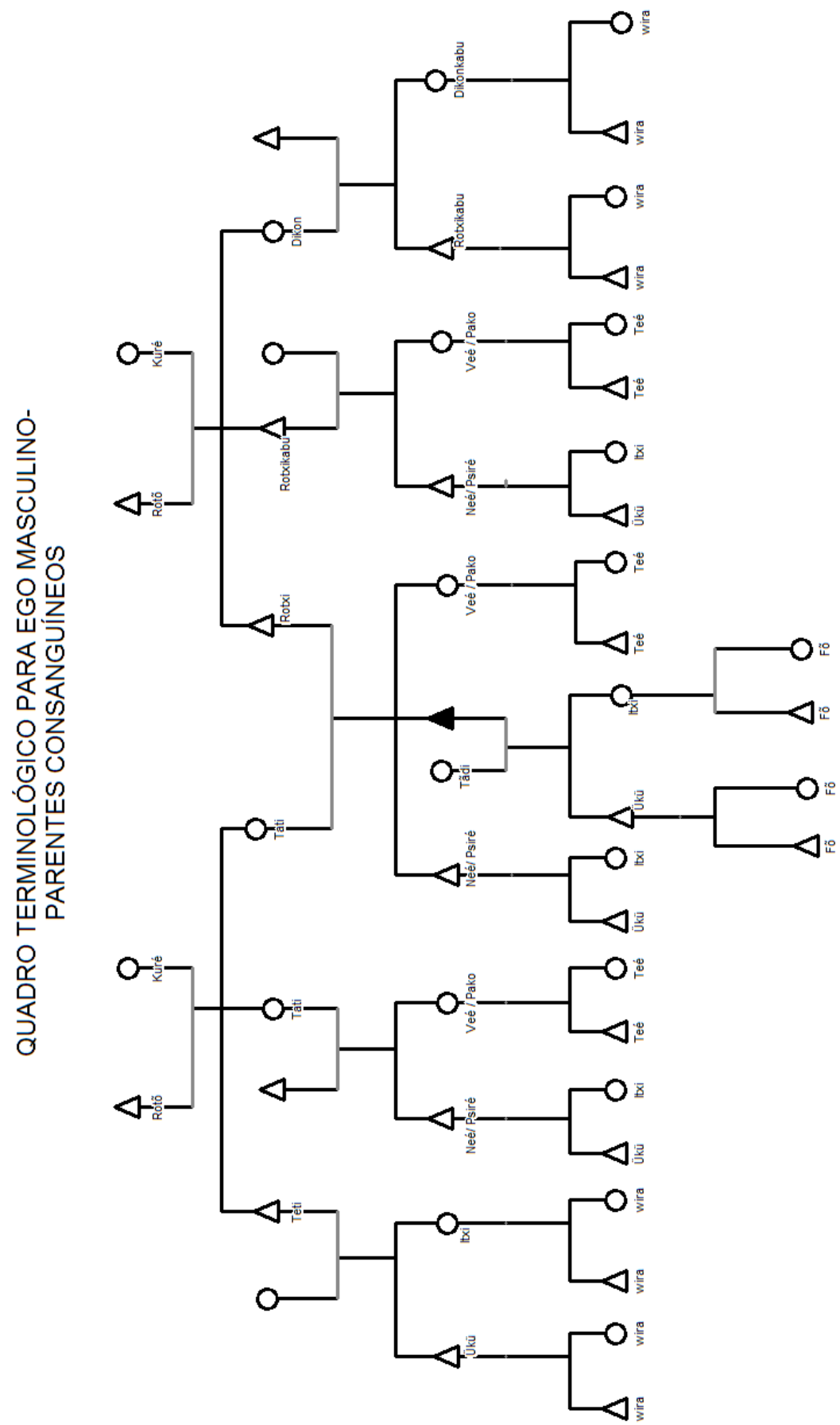


Figura 2 - Quadro terminológico para Ego feminino (parentes consanguíneos)

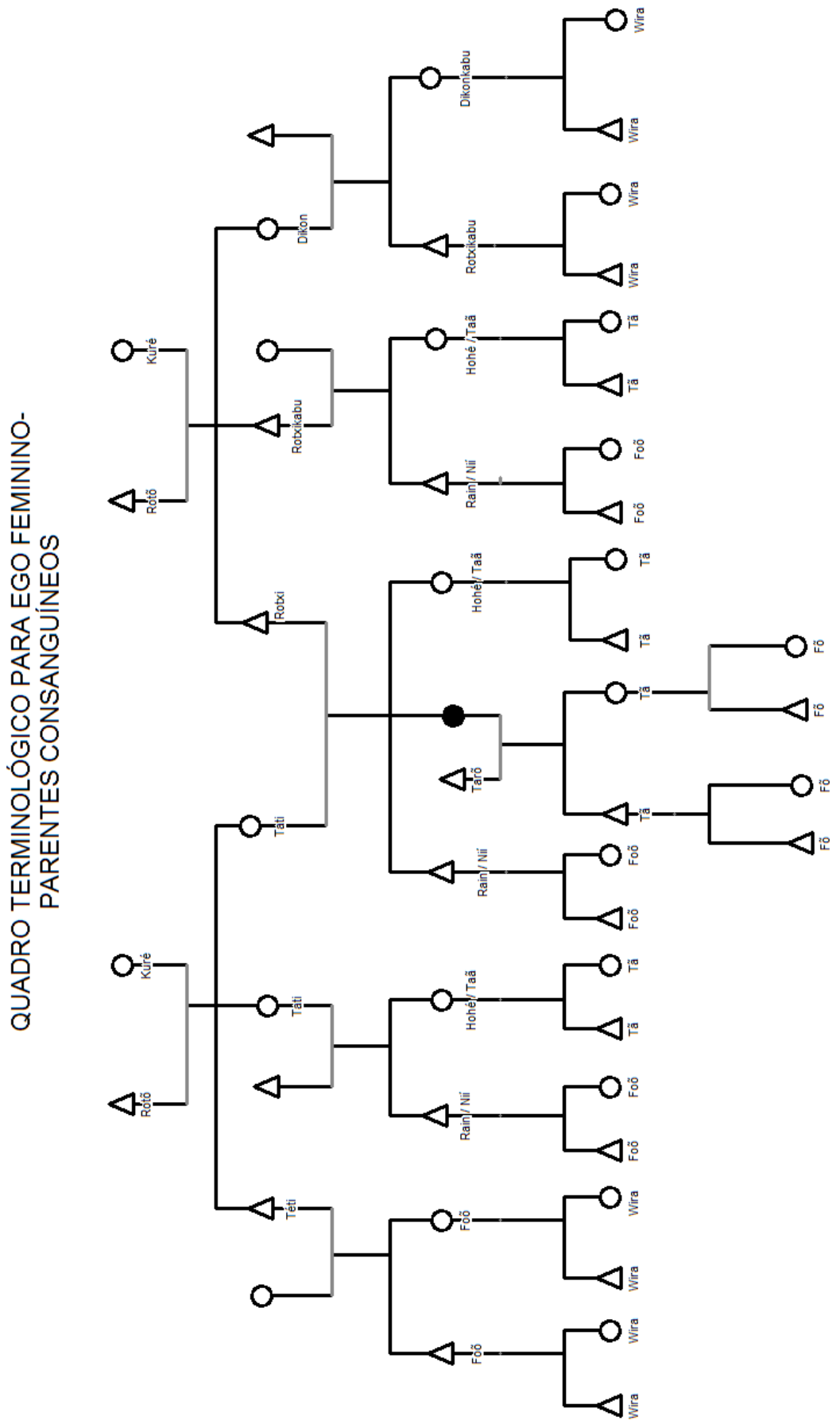


Quero notar primeiramente que, em relação a siblings, Ego masculino e Ego feminino usam um conjunto de termos distintos. Além disso, na terminologia djeoromitxi estão presentes equações oblíquas de feição Crow: "a classificação dos primos cruzados obedece em geral [...] a assimilação dos patrilaterais a F e FZ, e dos matrilaterais a 'filhos', para um homem, e a 'sobrinhos' para uma mulher" (Coelho de Souza, 2002:463). Essas equaçôes se aplicam sobre uma terminologia de "duas seçóes", que reparte os cognatos em duas categorias segundo o critério do cruzamento $(\mathrm{F}=\mathrm{FB} \neq \mathrm{MB} ; \mathrm{M}=\mathrm{MZ} \neq \mathrm{FZ})$, mas sem estender essa divisão aos parentes em $\mathrm{G} \pm 2 .^{8}$

Além das equações oblíquas, que já neutralizam o cruzamento em G0, consanguinizando os primos cruzados, pode-se observar, no plano das atitudes, uma "havaianização" que se expressa por meio da partilha de alimentos, da colaboração nos trabalhos e do respeito que se deve observar com todos primos, cruzados ou paralelos, incluindo os uterinos e residencialmente distantes. É preciso, pois, observar que os termos para a posição de prima cruzada patrilateral (FZD) foram bastante difícies de estabilizar de modo a compor a tabela acima. Para Ego masculino, por vezes essa prima aparecia como itxi (filha); por outras, ela aparecia como dikonkabu ("outra tia paterna"), ao passo que seu irmão (FZS) sempre apareceu como hotxikabu ("outro pai”; F=FB). Para Ego feminino, ora o termo hotxikabu era aplicado para FZS e MBS, ora essas posiçóes eram distinguidas e MBS aparecia como foó (filho de irmão para Ego feminino).

Em que pesem tais variaçôes, considerando os termos recíprocos, a alternativa itxi (=D) para FZD de Ego masculino e hotxikabu (=F) para MBS de Ego feminino parece ressoar a possibilidade de casamento amital. No caso do casamento amital, a posição FZS é igual a $S$, para Ego masculino, e $\mathrm{H}$, para Ego feminino. Por outro lado, dikonkabu para FZD (=FZ) de Ego masculino e foó para MBS (=BS) de Ego feminino (equaçóes crow) ainda me soam como um enigma. A alternância entre essas possibilidades é ainda mais enigmática se considerarmos que o termo hotxikabu $(=\mathrm{FB}=\mathrm{F})$ para FZS tanto de Ego feminino quanto de Ego masculino não parece sujeito a variaçóes. Seja como for, essa instabilidade para os primos cruzados não parece um privilégio ou problema isolado, e creio podermos avançar por meio dela, e não somente apesar dela.

Também Coelho de Souza (1995) observou essa característica para povos xinguanos, assim como Fausto (1995), para os Parakanã e os Tupi-Guarani, e Viveiros de Castro \& Fausto (1993) a generalizaram para a Amazônia. Viveiros de Castro, por exemplo, interpreta a posição liminar dos primos cruzados como uma "espécie de casa vazia diferencialmente preenchida por cada configuração particular" (1996:83). O autor sublinha a possibilidade de um dravidinato 
“terminologicamente subespecificado", mas com a condição estrutural de uma oposição não neutralizável em $\mathrm{G}^{1}$ entre consanguíneos e afins, que comandaria "a transmissão de afinidade nas geraçóes subsequentes” (Viveiros de Castro, 1996:83). Essa mesma subespecificação, tanto quanto a não neutralizaçáo da diferença entre consanguíneos e afins em $\mathrm{G}^{1}$, parece vigorar no caso djeoromitxi, implicando a instabilidade e ambiguidade que incidem sobre a posiçáo dos primos cruzados.

Tendo isso em vista, comecemos a análise pela categoria que parece compensar essa consanguinização dos primos cruzados, a última categoria do quadro, a categoria wirá, que recobre os cônjuges preferenciais, sendo eles filhos de primos cruzados ( $\mathrm{FZChCh;} \mathrm{MBChCh}$ ) e, reciprocamente, primos cruzados dos pais (FMBCh; FFZCh; MFZCh; MMBCh). Tendo por base que a categoria wirá codifica os cônjuges preferenciais, note-se que essa categoria afiniza retrospectivamente aquelas posiçóes que foram consanguinizadas em G0: os primos cruzados e os pais de primos cruzados "tornam-se" sogro e sogra, embora se tenha termos de afinidade separados.

A categoria wirá é reconhecida, pelos outros povos indígenas que ali convivem, como uma categoria djeoromitxi para cônjuges preferenciais e para a amizade e companheirismo entre pessoas de mesmo sexo. Em relação à tradução do termo, certa vez um amigo wajuru, filho de Pacoreiru Djeoromitxi, me disse tratar-se dos "compadres". Outro amigo wajuru me disse ainda serem os wirá análogos aos "companheiros", chamados por ogüaiküp na língua wajuru. Ademais, como pude saber de uma interlocutora makurap, em sua língua os "companheiros" (wirá, em djeoromitxi) chama-m se auké. Não tenho certeza se as categorias wajuru e makurap corresponderiam, como na djeoromitxi, às posiçóes de cônjuges preferenciais, embora ache provável que sim.

É verdade que tive notícias de casamentos amitais no passado - que se poderia relacionar com a obliquidade terminológica —, todavia, do ponto de vista do sistema que pude observar e que aqui descrevo, as equivalências $\mathrm{FZD}=\mathrm{D}$ e $\mathrm{M}=\mathrm{FFZ}$ (coerentes com o caso amital) não são efetivamente realizadas. Em seu lugar, podemos obervar as equaçóes crow $\mathrm{FZD}=\mathrm{FZ}$ e $\mathrm{MBD}=\mathrm{D}$, para Ego masculino. Voltarei a esse ponto adiante; por ora, considerando tais equaçóes $(\mathrm{FZD}=\mathrm{FZ}$ e $\mathrm{MBD}=\mathrm{D})$, os cônjuges preferenciais para Ego masculino, filhas de sua prima cruzada (suas wirá) seriam, no primeiro caso, classificadas como 'FZD' e, no segundo caso, como 'DD'. Nesse raciocínio, não levo em consideração as possíveis equaçóes crow em G-1, que, no caso djeoromitxi, são justamente bloqueadas pela categoria wirá. O que a categoria wirá faz é limitar ou bloquear a consanguinização implicada pelas equaçóes oblíquas crow para além de G0, pois no nosso caso elas só funcionam nessa geração. 
Sendo assim, pode-se dizer que a intergeracionalidade é intrínseca aos wirá. Entretanto, o que precisa ser ressaltado é que a afinidade se introduz a partir da segunda geração. O sistema djeoromitxi, de terminologia oblíqua e feiçóes majoritariamente crow, implica proibiçóes dos cognatos cruzados em G0, mas não as estende para as geraçôes adjacentes. Assim, a categoria wirá cobre certas posiçóes que seriam, do ponto de vista dravidiano e iroquês, paralelas (' $\mathrm{F}$ ' $\mathrm{Ch}$ ), cruzadas ('FZ'Ch;(m) 'Z'Ch; (f) 'B' Ch) e neutras ('Ch'Ch). Vê-se, então, que a categoria wirá (ou a afinidade) implica, no caso djeoromitxi, a violação da regra de "ascendência uniforme" elaborada por Sol Tax, a saber, "if somebody whom Ego calls A has parents whom ego calls B, them the parents of all who are called A are B" (1955:20). Um wirá pode ser, por exemplo, para Ego masculino, filho ou filha de uma 'FZ' (Dikon) ou de uma 'D' Ch (Fô), e filho ou filha de um 'F' ou de um 'S'.

Sendo wirá uma categoria de afinidade (os wirá são cônjuges preferenciais), é possível associá-la a um princípio de cruzamento? Se sim, qual seria a forma desse princípio? Se quisermos manter a hipótese de que cruzamento expressa afinidade ou desposabilidade, que tipo de sistema teríamos aqui? Minha pergunta é bastante inspirada naquela formulada por Coelho de Souza para o caso xinguano: "saber em que medida o cruzamento não-dravidiano (isto é, não dedutível do princípio $\mathrm{MBCh} / \mathrm{FZCh}=\mathrm{H}, \mathrm{W})$ se relaciona à afinidade é obviamente um dos problemas a solucionar" (1995:132). Como no Alto Xingu, também estamos diante de "um complexo sistema de interação cujas aldeias exibem 'uma cultura material de notável homogeneidade, [...] e relaçôes cerimoniais, comerciais e matrimoniais entre elas' (Steinen 1940 [1884])" (Coelho de Souza, 1995:121). No ambiente regional xinguano, grosso modo, pode-se observar um cruzamento de tipo iroquês em G-1e, por vezes, uma deriva havaiana em G0. Essas características são aliadas a uma terminologia específica de afinidade que compromete, segundo a autora, "a prescritividade do sistema, refletindo a incorporação de não-cognatos no campo matrimonial” (Coelho de Souza, 1995:132).

O caso djeoromitxi guarda evidentes similaridades com os casos xinguanos: também apresentam uma cultura material homogênea em relação a outros povos que, talvez em decorrência disso ou vice-versa, são cerimônia e matrimonialmente aliados. Além disso, é comum às duas áreas a não observação do cruzamento dravidiano em G0, além da presença de terminologia específica de afinidade. Vejamos agora as discrepâncias em relação ao tipo de cruzamento observado nas duas áreas. Adianto: a categoria wirá parece expressar um cálculo de cruzamento de "tipo ngawbe" (com interferências oblíquas), enquanto no caso xinguano tem-se majoritariamente um cruzamento de tipo iroquês. 
Vejamos primeiramente as similaridades e discrepâncias de alguns cálculos de cruzamento para as posiçóes de filhos de primos. ${ }^{?}$

\section{Tabela 2 - Tipos de cruzamento}
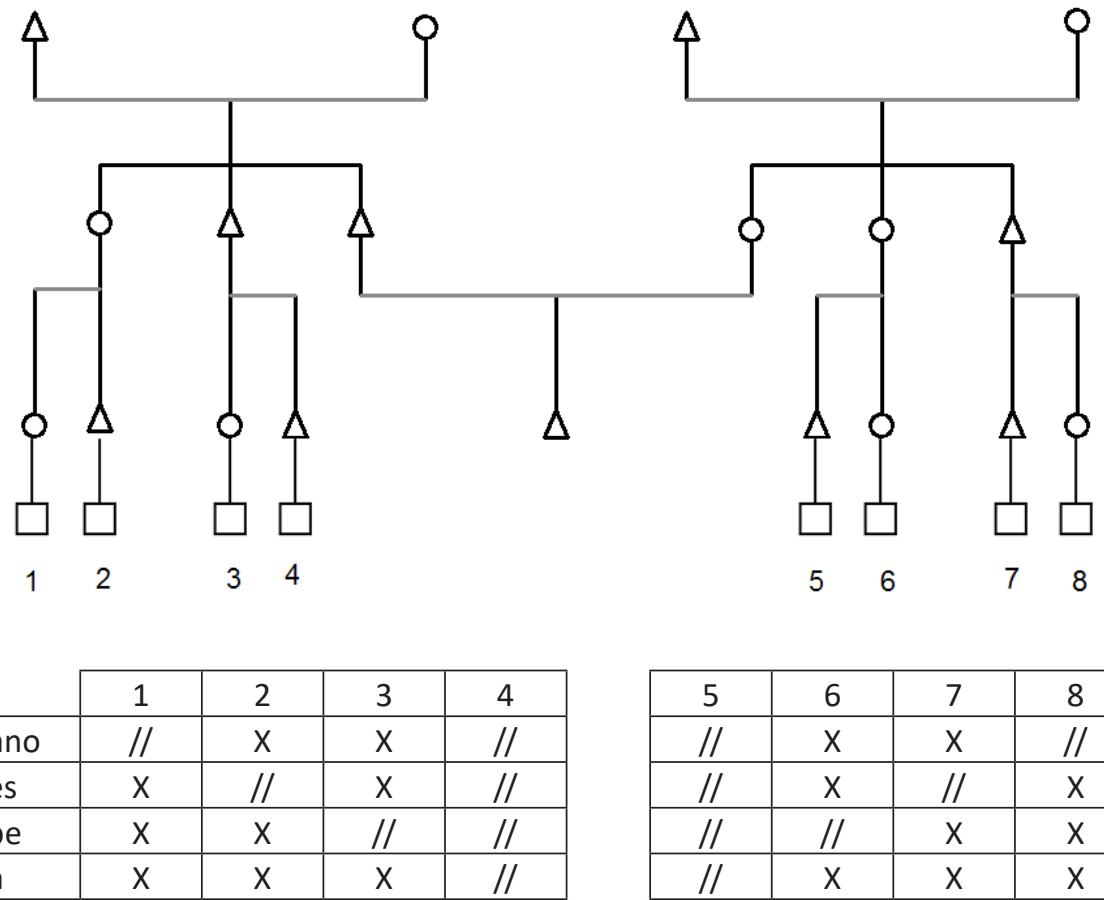

\begin{tabular}{|c|c|c|c|c|}
\cline { 2 - 5 } \multicolumn{1}{c|}{} & 1 & 2 & 3 & 4 \\
\hline Dravidiano & $/ /$ & $\mathrm{X}$ & $\mathrm{X}$ & $/ /$ \\
\hline Iroquês & $\mathrm{X}$ & $/ /$ & $\mathrm{X}$ & $/ /$ \\
\hline Ngawbe & $\mathrm{X}$ & $\mathrm{X}$ & $/ /$ & $/ /$ \\
\hline Kuma & $\mathrm{X}$ & $\mathrm{X}$ & $\mathrm{X}$ & $/ /$ \\
\hline
\end{tabular}

\begin{tabular}{|c|c|c|c|}
\hline 5 & 6 & 7 & 8 \\
\hline$/ /$ & $\mathrm{X}$ & $\mathrm{X}$ & $/ /$ \\
\hline$/ /$ & $\mathrm{X}$ & $/ /$ & $\mathrm{X}$ \\
\hline$/ /$ & $/ /$ & $\mathrm{X}$ & $\mathrm{X}$ \\
\hline$/ /$ & $\mathrm{X}$ & $\mathrm{X}$ & $\mathrm{X}$ \\
\hline
\end{tabular}

Nota: "X" corresponde a parente cruzado e "//" corresponde a parente paralelo.

Fonte: Essa tabela obedece aos tipos ordenados por Viveiros de Castro (1996:62).

Note-se que, enquanto no cálculo iroquês os filhos de primos cruzados de mesmo sexo são paralelos, no cálculo ngawbe estes seriam cruzados, como no caso dravidiano. Por outro lado, os filhos de primos cruzados de sexo oposto, paralelos no cálculo dravidiano, são aqui, como no caso iroquês, outra vez cruzados isto é, afins virtuais. É por isso que sugiro ler a categoria wirá como um caso de cruzamento ngawbe com inflexáo oblíqua. Como diz Viveiros de Castro,

o caso ngawbe é de certa forma o inverso do iroquês: enquanto neste último o sexo relativo só é levado em conta em G1, "coincidindo" com o cruzamento em G0, para os Ngawbe o sexo relativo só é importante na geração dos germanos iniciais (G2). Os zeros [paralelo] e uns [cruzados] poderiam ser apagados em G2 para o caso iroquês (como o faz aliás Trautmann) e em G1 para o caso ngawbe (1996:63). 
Ainda que a categoria wirá exiba uma inflexão oblíqua ausente no caso ngawbe, a codificação das posiçôes recíprocas [filhos de primos : : primos dos pais] é congruente com o cálculo ngawbe. Aqui, como lá, não é relevante, como o é no cálculo iroquês, o sexo relativo dos primos em questão, mas somente o cruzamento do casal de germanos iniciais.

Em todo caso, Viveiros de Castro também identifica um "sabor crow" para o caso ngawbe: FZ (=MBW) e FZH ( $\neq \mathrm{MB})$ são equacionados aos parentes em $\mathrm{G}^{2}$ (Young, 1971:140-8 apud Viveiros de Castro, 1996:60). Embora isso não ocorra entre os Djeoromitxi, eu falo ainda em ngawbe oblíquo para o seu caso, pois sua principal posição codificada como cruzada aqui é a de filhos de primos e primos dos pais, enquando para os Ngawbe a preferência pelo casamento é entre filhos de primos. Observo, somente, que essa última possibilidade também pode ocorrer entre os Djeoromitxi, principalmente quando alguns casamentos não foram, estrategicamente, levados a cabo entre aquelas pessoas que ocupam as posiçóes wirá, de modo a abrir novas alianças com outros entes trocadores. Nesse casos, podem-se casar, na próxima geração, os filhos de wirá, fazendo com que o ciclo de alianças entre dois entre trocadores (aqueles cujos membros incialmente ocupavam a posição wirá) seja re-estabelecido.

A categoria wirá pode implicar a desposabildade de parentes bilaterias, para Ego masculino, uma FFZDD=MMBDD, ou, ainda, uma FFZSD=MMMBDD. Por sua vez, o caso ngawbe não admite casamentos bilaterais, o que parece estar relacionado a seu sistema de filiaçâo. E aqui reside mais uma diferença com os Djeoromitxi. Vejamos.

\section{Entre a América Central e o sudoeste amazônico}

Os Ngawbe ou Guaymí Ocidentais, entre os quais esteve Philip Young, são uma população de língua chibcha, habitantes da porção montanhosa do oeste do Panamá. Young (1970) observa a havaianização terminológica que assimila a germanos - portanto, interditos — todos os primos imediatos, estendendo-se aos primos paralelos mais distantes. Todavia, ainda segundo o autor, os primos cruzados distantes não são recobertos pela categoria ngwae (germano de sexo oposto). Entre os Ngawbe, a forma preferida de casamento é a troca simétrica de irmãs entre dois grupos de parentesco, mas as alianças só são restabelecidas depois de duas geraçóes (Young, 1970).

No caso ngawbe, a aliança simétrica alia-se ao que Young (1970) chama de filiação simétrica: "an individual, male or female, receives patrifiliation from his or her father and matrifiliation from his or her mother. A man passes only his patrifiliation to his children, and a woman passes on only her 
matrifiliation" (1970:92). Suponho que isso corresponda ao que se conhece por "descendência paralela". Contudo, seria ainda possível pensar em "dupla descendência", pois, mesmo que fale em quatro patrilinhas e quatro matrilinhas, Young sustenta sua demonstração do sistema de aliança em seçôes mistas (A1, B2, etc., sendo o princípio masculino representado por letras, e o feminino, por números, num total de 16 secçóes possíveis). ${ }^{10}$ Náo penso que seja o caso de tentar estabelecer uma definição precisa para a regra de filiação ngawbe, uma vez que, ali, patrifiação e matrifiliação não resultam em dois grupos (como é o caso da dupla descendência típica, i.e., um grupo territorial e /ou exógamo e, outro, ritual), mas num conjunto de classes matrimoniais. Sobre isso, um parênteses.

Como se sabe, a análise dos casos australianos como dupla descedência foi criticada por Lévi-Strauss (1982), que substitui a isso a ideia de regime desarmônico (descendência versus residência): a dupla descendência é mais clara em sistemas tipo ashanti, que exibem dois tipos de grupos distintos. No caso ngawbe, não é claro que a matrifiliação e a patrifiliação sejam dois estatutos, pois resultam na afiliação ao mesmo sistema de grupos, que se veem multiplicados pela interação dos dois princípios. O caso djeoromitxi, veremos adiante, parece aproximar-se mais da "filiação complementar" (Fortes, 1970), em que M e F transmitem ambos o "estatuto", a filiação ao seu próprio patrigrupo, mas sem a injunção de paralelismo ou simetria — diferente, então, do que ocorre na "dupla descêndencia" (e na "descendencia paralela”).

A filiação complementar foi definida por Meyer Fortes (1970). Ela se distingue tanto da dupla descendência, que suponho ser o caso ngawbe, quanto da descendência paralela. Grosso modo, como na descendência paralela, na filiaçáo complementar está em jogo apenas um estatuto, que mães e pais transmitem aos filhos. No entanto, na filiação complementar, pode-se dizer que é o mesmo estatuto que está sendo transmitido (referindo-se aos mesmos grupos grupos, clãs, linhagens), mas levando-se em conta que são duas maneiras conjuntas de relacionar-se a eles: uma plena, político-jural, que é a descendência, e a outra, que é a filiação, que pode ter implicaçóes jurais, mas residuais. $\mathrm{Na}$ descendência paralela, o estatuto é transmitido segundo um paralelismo de gênero ( $\mathrm{M} \rightarrow \mathrm{D} /$ $\mathrm{F}->\mathrm{S}$ ), ao passo que na filiação complementar esse paralelismo não existe. $\mathrm{Na}$ dupla descendência, dois tipos de filiação (materna e paterna) servem de base para a transmissão de dois estatutos diferentes: $(\mathrm{M} \rightarrow \mathrm{D} / \mathrm{S} / \mathrm{F}->\mathrm{D} / \mathrm{S}) .{ }^{11}$

Em relação à "filiação complementar", é claro que Fortes (1959) tinha em mente uma complementação ao pertencimento grupal, sendo este fortemente marcado pela descendência (atributos jurais transmitidos num idioma genealógico). Para o autor, filiação seria "the fact of being the child of a specified parent", 
e descendência, "the genealogical connection recognized between a person and any of his ancestors or ancestress" (1959:206-7). Assim, "only unilineally bounded groups may be called descent groups, and unilineal genealogical criteria for memberchip of groups may be called descent" (Scheffler, 1966:541). Nesse sentido é que Fortes teria restringido a categoria "grupo de descendência" para grupos em que, justamente, descendência é o único critério de pertencimento (Scheffler, 1985) e não somente a filiação. Segundo Scheffler (1985:8), Fortes "realised, that where a relationship of descent is jurally the basis of entitlement to a status, that relationship is bound to operate by placing persons in categories of group (1959:208)". Se essa relação de descendência é o que agruparia as pessoas, esse agrupamento seria necessariamente um grupo corporado, mesmo que "the corporate possesion is as imaterial as an exclusive common name or an exclusive cult" (Fortes, 1959:208 apud Scheffler, 1985:9). Essas definiçóes correspondem a uma noção de descendência baseada na continuidade linear e, mesmo no caso da filiação complementar, esta depende de um princípio jural: ambas noçóes discutíveis para o caso ngawbe e para o caso djeotomitxi. ${ }^{12}$ Fecha parênteses.

No caso ngawbe, diz Young, a filiação simétrica estabelece quatro patriclasses e quatro matriclasses (sendo possíveis dezesseis seçôes) por meio das quais o sistema de aliança pode continuar a funcionar. São quatro unidades "trocando bilateralmente irmãs conforme um ciclo de período 3" (Viveiros de Castro, 1996:61). Nesse caso, "patrilateral cross-cousin (FFZDD) [...] appears to be at least a theoretical preference. [...] It serves, for example, to re-establish the original alliance between groups when these groups are again reconstituted in Gx" (Young, 1970:90). O casamento com a prima cruzada matrilateral classificatória (MMBDD) também é possível, pois também nesse caso não são normalmente reconhecidos laços consanguíneos. Note-se que o primeiro tipo de parenta (FFZDD) é cruzado à iroquesa e paralelo à dravidiana, enquanto que, para o segundo tipo (MMBDD), as coisas se invertem. A parentela (kindred) ngawbe, no interior da qual o casamento é considerado incestuoso, é, ao mesmo tempo, residencial e egocêntrica. Nesse grupo, de inflexão virilocal, se por acaso existir uma FFZDD disponível, ela não será casável, posto que será ngwae (irmã) para Ego masculino. É o pertencimento ao grupo local que faz com que o laço consanguíneo seja reconhecido, e não a mera cognação, pois, diz Young, normalmente não se lembram os laços genealógicos com a FFZDD.

Há mais do que isso em relação à função da symmetric filiation entre os Ngawbe, pois ela tem o efeito de expandir o pertencimento à parentela, grupo no interior do qual o casamento é considerado incestuoso, e ao mesmo tempo limita as escolhas matrimoniais. Para ser casável, uma mulher só pode ser FFZDD 
ou MMBDD, e não ambas as posiçóes conjuntamente: "if a woman shares filiation with either parent of a man, she may not marry him, and, conversely, if a man shares filiation with either parent of a woman, he may not marry her (Young, 1970:92).

Já temos condiçôes de visualizar a transformação do sistema ngawbe implicada pelos wirá djeoromitxi. Trata-se de uma tranformação que combina a possibilidade ngawbe com a obliquidade do casamento, gerando também a possibilidade do casamento bilateral (FFZDD=MMBDD) (Young, 1970). Essa é uma maneira de tornar possível o redobramento de alianças de afins, aspecto que estaria bloqueado pelo casamento ngawbe.

\section{Passagens numéricas}

Até aqui, abordamos a terminologia djeromitxi e as diferenças entre os cálculos de cruzamento dos sistemas (dravidiano, iroquês, ngawbe e kuma) para as posiçôes de filhos de primos. Tendo já esclarecido que a categoria wirá codifica a afinidade, passemos agora às principais diferenças entre o casamento ngawbe e o casamento wirá, notando a transformação djeoromitxi sobre esse modelo de cruzamento. Em seguida, avaliaremos o redobramento de alianças realizado pelos Djeoromitxi.

\section{Figura 3 - Casamento ngawbe}
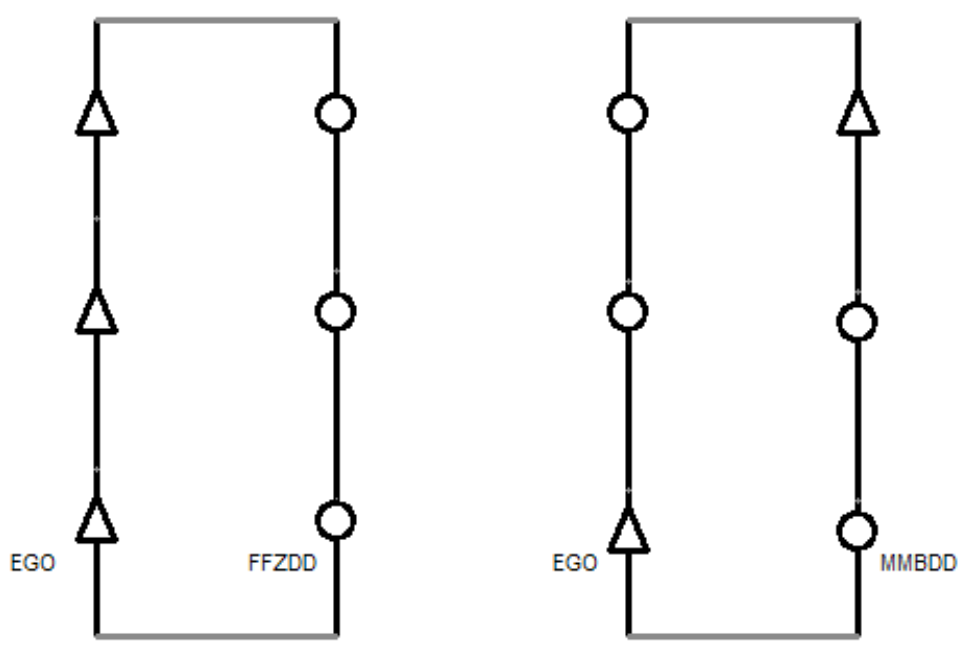

Fonte: Young, 1970:93 
Figura 4 - Casamento wirá
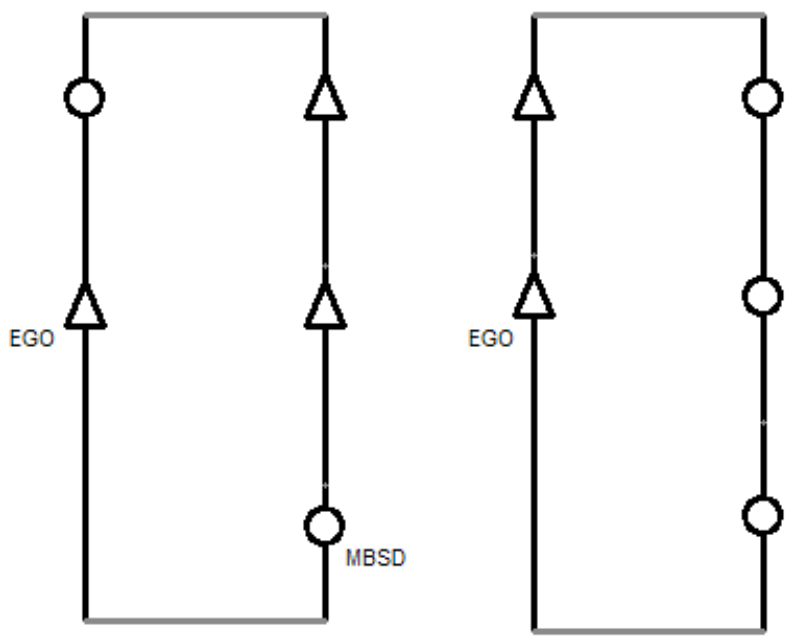

Fonte: Soares-Pinto (2014: 148)

Avaliemos a relação e o número de entes trocadores necessários, bem como a intergeracionalidade embutida no casamento wirá. Para o contraste inicial, tomarei aqui o modelo de casamento de primos cruzados bilaterais e o casamento wirá bilateral.

Figura 5 - Casamento de primos cruzados bilaterais

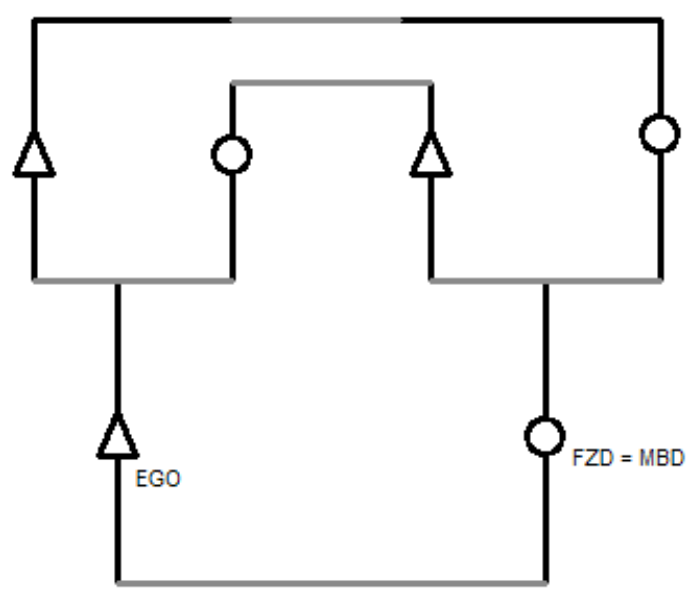

Fonte: Soares-Pinto, 2014: 149 
Figura 6 - Casamento de Wirá bilaterais

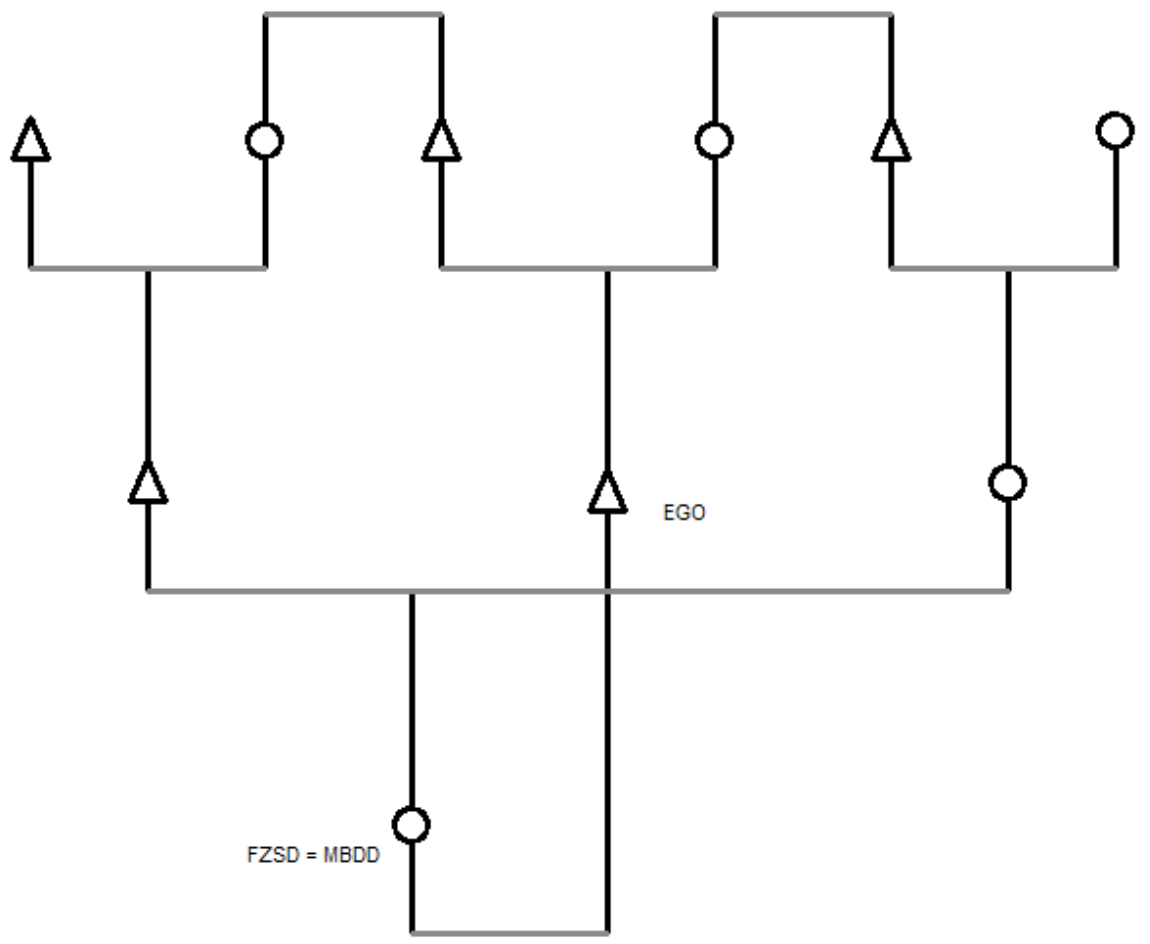

Fonte: Soares-Pinto, 2014: 150

Para a apreciação dos esquemas acima, é preciso também ter em mente que o sexo relativo dos primos cruzados é indiferente para o estabelecimento da relação e, assim, da possibilidade de casamento. Já vimos como o cruzamento wirá é diverso do iroquês, presente nos casos xinguanos em que, segundo Coelho de Souza (1995:174), "os cônjuges preferenciais seriam filhos de primos cruzados de sexo oposto, posições paralelas do ponto de vista dravidiano, mas cruzadas num sistema de tipo iroquês". A principal diferença entre o cálculo de cruzamento wirá e o sistema "iroquês" seria que, neste último, "o importante na classificação dos filhos de primos é o sexo relativo de Ego e o parente de ligação; filho de primo cruzado de mesmo sexo é igual a filho de germano de mesmo sexo" (Coelho de Souza, 1995:142). Essa equação não é válida para os wirá, pois o filho de primo cruzado, independente do sexo, é igual à cônjuge virtual. ${ }^{13}$

Mas os cálculos iroquês e wirá guardam semelhanças, principalmente quando pareados ao cálculo dravidiano. Neste último, o modelo de casamento de primos cruzados bilaterais exige dois casais de germanos de sexo oposto conectados pela troca de irmás e uma geração para o fechamento do ciclo. Por sua vez, o modelo de 
casamento de wirá bilaterais exige três classes ou três casais de germanos de sexo oposto e duas geraçóes para fechar o ciclo. Nesse caso, dois casais de germanos de sexo oposto acoplarão um terceiro (afim). É por esse acoplamento que o casamento bilateral poderá ocorrer na segunda geração posterior aos primeiros casamentos, já que os primos da primeira geração são interditos. Imaginando provisoriamente que o que serve para o regime iroquês serviria também para o regime dos wirá, a diferença, segundo sugere Viveiros de Castro, seria que

os sistemas dravidianos codificariam de modo "prescritivo" um sistema de trocas repetidas de irmãs em geraçôes consecutivas — ou seja, "casamento de primos cruzados bilaterais" - , ao passo que as configuraçóes iroquesas estariam associadas à troca de irmãs não-repetível em geraçôes consecutivas (note-se que não achamos equaçôes do tipo $\mathrm{MB}=\mathrm{WF}$ etc. em sistemas iroqueses), isto é, a um ciclo de troca mais longo, visto que os primos cruzados não funcionam "terminologicamente" como cônjuges ali (1996:51).

Com efeito, Viveiros de Castro (2002:112) já observou ser duvidosa a adequação do paradigma dravidiano elementar - terminologia de duas seções, aliança simétrica e inexistência de termos de afinidade separados - para casos amazônicos. O autor observa a difundida preferência avuncular e a inflexão patrilateral, mesmo nos casos de prescrição terminológica bilateral. O paradigma dravidiano na Amazônia, diz Viveiros de Castro, "é neutralizado nos desvios hawaianos e iroqueses; é infletido por equações oblíquas, [...] é descritivizado, no caso de termos separados de afinidade e designaçôes compostas; é linearizado, nos sistemas com classificação kariera" (2002:112).

No início de seu artigo "O problema da afinidade da Amazônia", o autor chama atençáo para o caso tupari como uma "cultura de floresta tropical", ao lado dos Sirionó e Pakaa-Nova (Wari'), que "utilizariam sistemas semelhantes aos centros-brasileiros" (Viveiros de Castro, 2002:89), isto é, sistemas distintivos por sua "terminologia sem correlatos matrimoniais claros, que evocam, em suas equaçôes oblíquas, o tipo crow-omaha" (Viveiros de Castro, 2002:89). Adianto que não possuo dados sobre a terminologia tupari (vizinhos e afins dos Djeoromitxi), mas penso que o caso djeoromitxi possa de fato corroborar a intuição do autor sobre o caráter transicional entre a Amazônia e o Brasil Central desses grupos habitantes da bacia do Rio Madeira (rios Guaporé e Mamoré). No entanto, a ausência de codificação terminológica do casamento (interdição geral sobre todos os cognatos) dos povos do Brasil Central difere do que encontramos entre os Djeoromitxi. E esse parece um elemento essencial para a possibilidade de caracterização do casamento wirá. 
Viveiros de Castro (1996) diz que o regime de aliança da maioria das sociedades indígenas da Amazônia é um regime multibilateral, isto é, não redutível a duas macroclasses ou dois parceiros de troca (metades), podendo emergir em sistemas de $2 \mathrm{n}$ classes matrimoniais. A troca multibilateral possui um "grau de liberdade" a mais que o sistema bilateral, pois "ignora ou aplica de modo limitado o cálculo definidor da troca restrita exclusiva ou global, a saber: aliado de aliado é consanguíneo, o casamento com afins de afins é interdito". Para Viveiros de Castro (1996:16), é este último cálculo que de fato permite "o reagrupamento das 2 n classes de um sistema de troca restrita exclusiva em 2 superclasses", para a fórmula global, e a irredutibilidade a 2 superclasses para fórmulas locais. A fórmula local, por sua vez, floresce em ambientes amazônicos, sugere Viveiros de Castro (1996), onde casar como um parente não significa casar com um parente — isto, é, o redobramento de alianças não é igual a um fechamento consanguíneo (bouclage). Isso é o mesmo que dizer que o casamento com um cognato cruzado, na Amazônia, é a redução elementar de uma estrutura de repetição de alianças que não possui inscrição genealógica a priori (Viveiros de Castro, 1996), mas que necessita do tempo, isto é, da história de relaçóes, para ser efetivada. Sendo assim, a “especificidade genealógica do cônjuge como 'cruzado' é um caso-limite de sua determinação categorial como afim” (Viveiros de Castro, 1996: 35).

Isso significa que na Amazônia está em jogo uma troca multibilateral, que poderia fazer emergir classes matrimoniais num sistema $2 \mathrm{n}$, desde que elas não sejam redutíveis a duas macroclasses (ou metades). $\mathrm{O}$ autor argumenta que o casamento bilateral entre filhos de primos requer pelo menos quatro objetos, isto é, quatro pares de germanos (Viveiros de Castro, 1996:51). As questóes intrínsecas a esse problema me parecem imprescindíveis para caracterizarmos o regime de alianças djeoromitxi. Um sistema de quatro objetos que interdita o casamento com primos cruzados de $1^{\circ}$ grau, prescrevendo a troca bilateral entre filhos de primos, permite, segundo Viveiros de Castro, duas soluçóes:

1. A solução "aranda" faz $\mathrm{AC} / \mathrm{BD}, \mathrm{AD} / \mathrm{BC}$ e novamente $\mathrm{AC} / \mathrm{BD}$; ela agrupa assim as "metades" A+B [=] C+D. Trata-se de um modelo sociocêntrico, de repetição de alianças a cada 2 geraçóes, que respeita o cálculo "aliado de aliado = consanguíneo" (redução $2 \mathrm{n} \rightarrow 2$ ).

2. A solução "iroquesa" consiste em admitir a união bilateral de cada unidade com as três outras, sequencialmente, em gerações consecutivas: $\mathrm{AB} / \mathrm{CD}, \mathrm{AC} /$ $\mathrm{BD}, \mathrm{AD} / \mathrm{BC}$, e novamente $\mathrm{AB} / \mathrm{CD}$. Trata-se de um modelo egocêntrico, de repetição a cada 3 geraçóes, onde cada classe "vê" as demais distribuídas igualmente à sua volta como afins: aliados de aliados serão também aliados (1989:16). 
O autor chama a segunda solução de iroquesa, mas faz algumas observações sobre esse ponto, em relação à alternativa entre o método de classes (fórmula global) e o método de relaçôes (fórmula local) ali operante. Ele completa: "variantes deste modelo que operam com o 'método das relaçóes' - sem classes — parecem se encontrar na América do Sul: os Ngawbe (Guaymí) do Panamá (Young, 1970), alguns grupos do conjunto Jívaro (Taylor, 1989)" (Viveiros de Castro, 1989:17). Segundo o autor, a troca de irmãs não repetida em geraçôes consecutivas seria característica dessas variaçôes. Esse parece ser também o caso djeoromitxi: embora o casamento de wirá bilaterais exija três entes trocadores, encontramos entre os Djeoromitxi casamentos realizados com filhos de wirá, e entre filhos de wirá. Abordemos agora a rede de redobramento de alianças djeoromitxi para melhor avaliarmos se as características da "solução iroquesa" se aplicam ali.

\section{Entre o sudoeste amazônico e o Brasil Central: casar-se como um parente}

No quadro abaixo, apresento uma amostra dos casamentos ocorridos, atentando principalmente para os casamentos realizados pelos filhos e filhas de Kubähi Djeoromitxi e Wadjidjiká Arikapô, casal de chefes da aldeia Baía das Onças. Apresento, ainda, a rede de afinidade em que estão envolvidos, que inclui outras aldeias da Terra Indígena Rio Guaporé.

\section{Figura 7 - Amostra de casamentos}

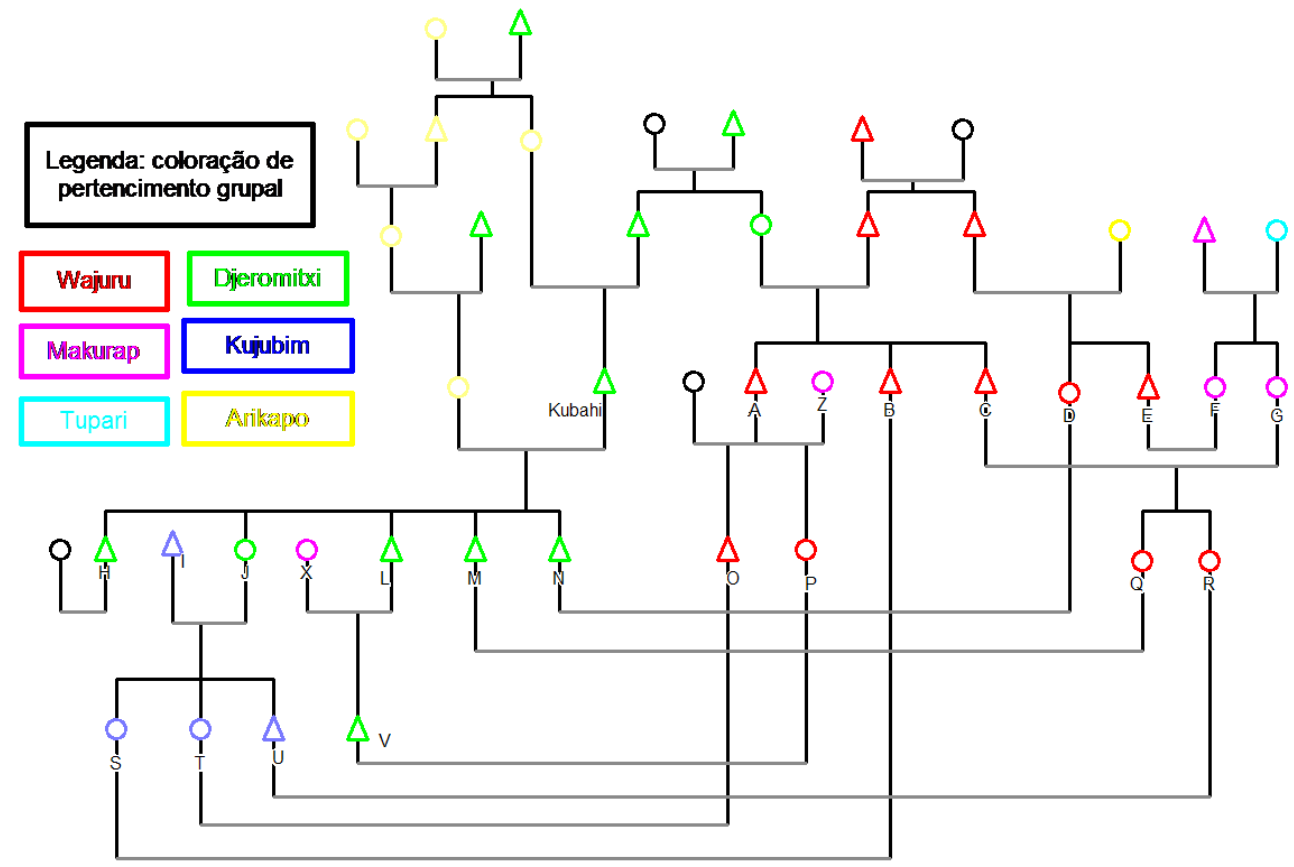

Fonte: Soares-Pinto, 2014: 154 
$M$ e $N$, filhos de Kubähi, casaram-se com suas FFZH'D', que são, ao mesmo tempo, suas FMZSD e suas MMMZSD. $V$, sobrinho uterino desses homens, casou-se com sua FFFFZSD. $B$ e $O$, afins de Kubähi, casaram-se, o primeiro, com sua MBSDD e, o segundo, com sua FMBSDD. Notemos entáo, primeiramente, que os matrimônios realizados pelos filhos de Kubähi e pelos filhos da FZ desse homem, wirá entre si, têm a propriedade de embaralhar as distinçóes entre ciclos longos e ciclos curtos de reciprocidade. Se num primeiro momento poderiam parecer se estender, quando se incorpora mais um "grupo de troca", como os Kujubim ou os Makurap, entretanto, não só os ciclos tornam-se mais curtos, mas o casar-se como um afim se faz importante para entendermos os casamentos contraídos pelos filhos e alguns netos de Kubähi.

Uma primeira questão que podemos observar nessa diagrama são estratégias matrimoniais de encurtamento de ciclo, segundo relaçóes de reciprocidade de tipo avuncular: ego masculino cede uma filha classificatória e recebe uma irmã de alter. Um exemplo desse tipo é a relação entre os indivíduos " $B$ " e " $U$ " no quadro acima, sendo " $S$ " esposa de " $B$ " e filha de " $J$ " (“J" é wirá de " $B$ "). Assim, " $U$ " é, ao mesmo tempo, cunhado e genro de " $B$ ". Esse mesmo caso pode ser observado se admitimos sua transformação no tipo de reciprocidade "ego dá uma filha classificatória e alter oferece em troca uma sobrinha real, filha de irmâ", que pode ser observado entre os indivíduos " $B$ " e " $M$ ". Sendo " $B$ " e " $M$ " wirá entre si, " $B$ " é ao mesmo tempo sogro de " $N$ " e genro " $I$ ", que por sua vez é cunhado de " $N$ ".

Uma segunda questão que se pode observar no diagrama refere-se aos casos de replicação de aliança de consanguíneos de mesmo sexo, o que Kaplan (1972) chamava de "afinidade serial": ${ }^{14}$

a) os casamentos contraídos por “ $C$ ” e " $E$ ” (irmãos classificatórios) com duas irmãs reais ("F" e "G");

a) os casamentos de " $M$ " e " $N$ " (irmãos reais) com mãe e filha classificatórias (“D” e “Q”);

a) os casamentos de " $B$ " e " $O$ " (pai e filho classificatórios) com duas irmãs reais (“ $S$ " e " $T$ ");

Uma terceira questão seria posta pelos casamentos contraídos por consanguíneos de sexo oposto ("O" e " $P$ ") com primos cruzados entre si (" $T$ " e " $V$ "). Num ambiente dravidiano, esses seriam casamentos com afim de afim. Esse tipo de casamento difere do tipo anterior: enquanto aqueles dispóem consanguíneos 
de mesmo sexo casando-se com consanguíneos de mesmo sexo, o caso em tela coloca consanguíneos de sexo oposto casando-se com consanguíneos de sexo oposto (considerando que são consanguíneos todos os primos na terminologia djeoromitxi, na medida em que vigoram as equaçóes crow). Note-se, assim, que este pode ser considerado um caso de transição entre os casos acima e um quarto caso: os wirá " $A$ " e " $L$ " casaram-se com mulheres makurap que são irmãs classificatórias entre si (" $X$ ” e " $Z$ ”), o que não impediu que os filhos de ambos, " $P$ " e " $V$ " (irmãos uterinos classificatórios), tivessem, eles mesmos, um filho, ainda que seu matrimônio não tenha persistido.

Notemos agora uma quinta questão: o casamento entre " $U$ " e " $R$ ", embora se pareça com um caso de "afinidade serial", notado acima para outros casamentos, permite a extração de outros problemas. $\mathrm{O}$ marido, " $U$ ”, assim como seus $\mathrm{MB}$, " $M$ " e " $N$ ", tomou uma mulher wajuru (" $R$ ") como esposa. Com efeito, as esposas de " $M$ " e " $U$ " são irmãs reais. " $M$ " e " $N$ " são, numa certa medida, afins de " $U$ " e, por esse motivo, pode-se dizer que " $U$ " casou-se como um afim. Do ponto vista categorial, " $U$ " replica uma aliança de consanguíneo (de seu tio materno), mas do ponto de vista grupal ele se casa com uma consanguínea dos afins de seu pai. No que concerne ao cálculo wirá, os filhos de " $M$ " e " $N$ " poderão ser tomados em casamento pelos filhos de " $U$ ", restabelecendo um ciclo matrimonial não redutível a duas macroclasses (do ponto de vista grupal), como o foi o casamento entre " $U$ " e " $R$ ".

Esse "casar-se como um afim", ou com afim de afim, evoca um exemplo etnográfico Jê. No caso mebengokre, diz Vanessa Lea (1995), os casamentos são pensados como preferíveis quando uma mulher se casa com o amigo formal de sua mãe. A autora sustenta que "as mulheres se casam 'do lado' da mãe (com um amigo formal da M), e os homens, 'do lado' do pai (com a filha de uma amiga formal deles e de seu pai)" (Lea, 1995:332). No modelo especulativo elaborado por Lea a partir dessas formulações, os amigos formais são sempre FFZDC = MMBSC e, portanto, obedecem ao cálculo de cruzamento iroquês - posiçóes que, note-se, correspondem no caso djeoromitxi a filhos de wirá.

Poderíamos transpor esse mesmo resultado para o modelo djeoromitxi, susbtituindo o amigo formal mebengokre pela categoria wirá. Se mantivermos a restrição da irredutibilidade a duas macroclasses, na situação em que um homem se case com a filha de sua wirá, evidentemente o pai da moça está dando sua filha para os wirá daqueles que lhe cederam uma esposa. Assim, no que diz respeito ao modelo de aliança proporcionado pelo cruzamento wirá (também amigos "informais" para alter e ego masculinos, mas este é um outro ponto), pode-se dizer que ele gera resultados em parte análogos à amizade formal mebengokre. 
Nesse sentido, permanece verdadeira para o caso wirá a seguinte afirmação de Lea sobre os amigos formais mebengokre: "em troca das mulheres cedidas às outras patrilinhas, cada patrilinha recebe mulheres dos amigos formais de seus próprios receptores de mulheres: os amigos formais de meus wife-takers são meus wife-givers" (1995:336)". No caso djeoromitxi, o contrário também é verdadeiro: os wirá de meus wife-givers são meus wife-takers. Um exemplo é o casamento entre um homem wajuru e uma mulher kujubim, filha de mulher kurupfü (que receberam como marcação as letras " $B$ " e " $S$ ”, respectivamente, no quadro acima).

Notamos na Figura 7 os seguintes padrōes de replicação de alianças: relaçóes de reciprocidade de tipo avuncular; aliança de consanguíneos de mesmo sexo; casamentos de consanguíneos de sexo oposto com primos cruzados entre si; casamentos de wirá (afins) com irmãs classificatórias; e casamento com consanguíneos de afins de consanguiíneo.

As uniôes com "afins de afins" indicam que também aqui é válido o apontamento de Coelho de Souza para os casos de casamentos intertribais xinguanos: "embora exógamos do ponto de vista local, são endógamos do ponto de vista das parentelas amplas que este sistema de aliança parece capaz de articular [...], uma estratégia que confirmaria [...] que uma mulher cedida deve ser devolvida" (1995:187, grifo no original). Mas é digno de nota que os filhos de Kubähi não se casaram com os filhos da tia paterna deste último, embora com eles mantenham relaçóes wirá de mesmo sexo. Foram os filhos desses wirá que reiteraram a relação de aliança primeiramente ocorrida entre a tia paterna de Kubähi e um famoso pajé Wajuru. Tudo indica que se utilizaram da colateralidade da rede de seus própios aliados (casando-se com consanguíneos de wirá), bem como da suspensão temporária da reiteração de certas alianças (primeiramente articuladas no casamento da tia paterna de Kubähi), para que pudessem "costurar uma rede mais ampla” (Coelho de Souza, 1995:196), incluindo mulheres makurap, e um homem kujubim, que mais tarde forneceu mulheres para os wirá de seus wifegivers (a parentela de Kubähi).

Do ponto de vista feminino, uma mulher poderá se casar com o filho de sua prima cruzada patrilateral ou com o neto de sua avó paterna. Tendo em vista o casamento com obliquidade geracional, por um lado, para Ego feminino, sua filha se casa com seu BSS ( fó; neto) e, para Ego masculino, sua filha se casa com o seu 'F' (FZS: Hotikabu, "pai outro"). Ou, para Ego feminino, seu filho se casa com sua BSD ( $f o ̂$, neta), e, para Ego masculino, seu filho de casa com sua 
'FZ' (FZD: Dikonkaku, “outra tia paterna”). Por outro lado, para Ego feminino, seu filho poderá se casar com sua MBD (foó, sobrinha), e para Ego masculino, sua filha poderá se casar com sua ZDD ( $f o ̂$, neta). Assim, um homem terá como sogro o seu MMB (hotó, avô), e sua esposa terá como sogra sua 'FZ' (FZD: Dikonkaku, "outra tia paterna”), e vice-versa. Dito isso, é possível pensar que os Djeoromitxi empregam a relação wirá para apagar os laços de consanguinidade e tornar casáveis as 'FZ' de seus pais, assim como desposar as netas de suas próprias mães, ou as suas próprias "sobrinhas".

Esses aspectos nos aproximam bastante do caso umeda da Nova Guiné, etnografado por Gell (1975 apud Viveiros de Castro, 1996). Nesse caso, estão em interação quatro patrilinhas terminológicas: o grupo de Ego; os grupos de afins reais ou potenciais de Ego; os grupos com quem o grupo de Ego trocou mulheres na geração anterior (aqui se acham os primos cruzados); os aliados de geraçóes anteriores (os primos cruzados do pai de Ego, ou filhos de primos cruzados pertencentes a essa categoria na geraçáo de Ego). Diz Viveiros de Castro ser a quarta categoria fonte da segunda, "em um ciclo onde a posição dos grupos ligados por aliança se desloca de um grau a cada geração” (1996:55). Resumidamente, lá, como cá, “o sistema de casamento transforma realmente 'afins' em 'parentes' (pois os aliados se tornam não desposáveis). A terminologia de parentesco, ao registrar um deslocamento do estatuto dos grupos ligados ao de Ego, transforma 'parentes' em afins, ou antes, em afins potenciais” (Viveiros de Castro, 1996:55). E não é exatamente isso que a categoria wirá realiza?

\section{Abertura}

Para encerrarmos, cabe retomar alguns pontos, primeiramente dizendo o seguinte: a categoria wirá exprime um cruzamento de tipo ngawbe com interferência oblíqua; o sistema deve operar com no mínimo três entes trocadores, num regime em que aliado de aliado é também aliado, ou quatro entes (objetos não redutíveis a $2 \mathrm{n}$ ). Além de casamentos com wirá, há casos de casamentos com filhos de wirá. No que diz respeito ao redobramento de alianças, Ego masculino casa-se com uma consanguínea de seu wirá/afim, ou como um afim/wirá. Esse aspecto compromete a transitividade do sistema, que definiçóes restritas de aliança supunham ser imprescindível para falar em aliança (Coelho de Souza, 1995; Viveiros de Castro, 1989). Como nos casos xinguanos, aqui é prudente falar em aliança considerando a troca de mulheres em geraçôes não consecutivas.

É possível que estejamos diante de uma estrutura de aliança semicomplexa, seguindo asserçôes de Silva (2008) sobre os conceitos elaborados por Héritier em O exercício do parentesco, de 1981. Segundo ele, Héritier 
distingue dois conceitos operacionais das estruturas de aliança: o de fechamento (bouclage), isto é, o de casar com alguém de algum modo aparentado; e o redobramento, isto é, o de casar como no passado um parente se casou. Para a autora, uma estrutura elementar é aquela em que fechamento e redobramento coincidem; uma estrutura semicomplexa, aquela em que fechamento e redobramento, embora não coincidam, ocorrem em intervalos determináveis; e uma estrutura complexa, aquela em que fechamento e redobramento se dão sem que seja possível determinar sua periodicidade (Silva, 2008:305).

Seguindo essas observaçóes, o caso djeoromitxi parece tratar-se de uma estrutura semicomplexa de ciclo 2 ou 3, e apresenta uma ambiguidade entre um sistema de alianças com quatro (não redutível a 2 n) e três entes trocadores.

Essas modelagens são também possíveis nos casos em que se quer produzir um ciclo mais curto, cujo efeito muitas vezes é a possibilidade de manter os cônjuges próximos à casa dos seus pais, não os "perdendo", como se diz, para outros grupos virilocais de outras aldeias. Assim, a troca de cônjuges é exógama do ponto de vista do grupo patrifiliativo e muitas vezes local, a náo ser que, caso se conte com um chefe do calibre de Kubähi, ${ }^{15}$ também os homens de outras parentelas venham se reunir em torno dele - como também poderão os netos ou bisnetos desse chefe casarem-se entre si. Os cônjuges, deste último modo, são arranjados no interior desse grupo local, tendo por sogro e sogra, muitas vezes, um irmão ou irmã da avó ou avô com o qual conviveu na juventude (isto é, antes de se tornar marido ou esposa). É o que se pode visualizar, por exemplo, no casamento entre uma neta e um bisneto de Kubähi, wirá entre si.

Figura 8 - Casamento wirá no interior da parentela de Kubähi

Fonte: Soares-Pinto, 2014: 159

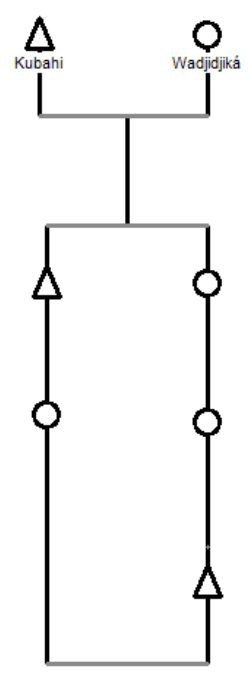

Anuário Antropológico, Brasília, UnB, 2016, v. 41, n. 1: 123-151 
Atualmente, o rapaz reside na casa do sogro (irmão de sua avó materna), a despeito do lamento incansável de sua mãe sobre as saudades que sente do filho recém-casado. Para avaliarmos o alcance dessa lamentação, é importante levar em consideração que entre as casas de ambos náo se perde mais que três minutos de caminhada. Essa tensão é muita vezes expressa em termos das lamentaçóes das mães dos rapazes, que, embora sobrinhas ('ZD') dos sogros de seus filhos, são de um grupo patrifilitivo diferente tanto de seus tios maternos quanto de seus próprios filhos. $\mathrm{Na}$ verdade, a tensão que pode estar em jogo é referente à relação de cossogras, o que significa muitas vezes a relação de uma mulher com a esposa de seu tio materno (MBW, que no esquema dravidiano seria uma $\mathrm{FZ}=\mathrm{HM}$ ).

Seria então preciso destacar que a distância espacial entre grupos locais acaba tensionando-os desde o seu interior, abrindo esses grupos para outras elaboraçóes e possibilitando ao "gradiente de distância" (Viveiros de Castro, 2002) se instaurar onde não é tão evidente. Mas essa já é outra história, que quiçá nos leve de volta ao "passado na maloca".

Recebido em 30/09/2015

Aprovado em 17/02/2016

Nicole Soares-Pinto é doutora em antropologia social pela Universidade de Brasília e pós-doutoranda em antropologia social no Museu Nacional/UFRJ. E-mail: nicsoares@gmail.com 


\section{Notas}

1. Agradeço especialmente a Marcela Coelho de Souza, orientadora da tese da qual este artigo é fruto, pelas inspiraçóes e pelos comentários críticos ao texto. A leitura de Márcio Silva e sua generosidade me ajudaram a formular o argumento, pois foi ele quem me chamou atenção para o tipo de cruzamento embutido no sistema de parentesco djeoromitxi.

2. Para maiores detalhes sobre as mudanças históricas e as movimentaçóes territoriais das famílias extensas desses povos, ver Soares-Pinto (2009, 2012, 2014).

3. Minha pesquisa de campo na Terra Indígena Rio Guaporé teve início em 2008. Desde então, passei mais de 13 meses em campo, visitando todas as suas aldeias. Como esclarecimento, é preciso dizer que meus principais interlocutores de pesquisa foram os filhos e netos de Kubähi Djeoromitxi e Wadjidjiká Arikapô: casal de velhos/chefes da aldeia Baía das Onças, onde convive principalmente sua família extensa — filhos e filhas, genros e noras, netos e netas.

4. Utilizo aspas simples para marcar termos ou kintypes em acepçóes classificatórias.

5. Dji:s.ind. "mãe", mas também s.ind. "osso", s.ind. "mucura” e v.tr. "colocar; guardar” (Ribeiro, 2008). Não explorarei tais homônimos porque me faltam dados etnográficos para tal.

6. Os símbolos obedecem à convenção antropológica: triângulo para homens, círculo para mulheres e quadrado quando a diferença de sexo não for pertinente.

7. Também pude saber das seguintes equaçóes: $\mathrm{D}$ para a prima cruzada patrilateral, do ponto de vista masculino, e F para o primo cruzado matrilateral, do ponto de vista feminino. Essas equaçôes poderiam ser consequências de um ciclo de casamento amital, hipótese que não deve ser descartada para os casamentos pretéritos, acontecidos num passado mais distante. Note-se, entretanto, que tais equaçôes são inconsistentes com as equaçôes Crow e com as equaçóes Omaha, que seriam as seguintes: para ego masculino, as primas cruzadas matrilaterais são $\mathrm{D}$ (Crow) ou $\mathrm{M}$ (Omaha), e as primas cruzadas patrilaterais se tornam FZ (Crow) e ZD (Omaha). Para ego feminino, os primos cruzados matrilaterias são $\mathrm{BS}$ (Crow) e $\mathrm{MB}$ (Omaha), e os primos cruzados patrilaterais são F (Crow) e S (Omaha). Sobre a terminologia Crow-Omaha, ver Lounsbury (1964); Trautmann \& Whiteley (2012); e Coelho de Souza (2002, 2011).

8. Utilizo a noção de "duas seçóes" apoiada em Murdock (1965) para me referir a todas as terminologias que operariam com as duas equaçóes $[\mathrm{FB}=\mathrm{F}$ e $\mathrm{MZ}=\mathrm{M}]$, a partir das quais os parentes paralelos se tornam estruturalmente redundantes. Ver Coelho de Souza (2002) sobre o princípio de equivalência entre germanos de mesmo sexo ou, nos termos da escola semanticista americana, uma "same-sex sibling merging rule" (Lounsbury, 1964; Parkin, 1996; Scheffler \& Lounsbury, 1971).

9. A definição mínima de cruzamento diz respeito à marca terminológica da diferença entre relaçóes em que um germano de mesmo sexo é o parente de ligação (paralelo) e 
aquelas em que um parente de ligação é um germano de sexo oposto (cruzado); em outras palavras, diz respeito à presença ou náo de mudança de sexo na passagem da linha direta para a colateral (Viveiros de Castro, 1996).

10. Utilizando letras para as quatro patriclasses $[\mathrm{A} ; \mathrm{B} ; \mathrm{C} ; \mathrm{D}]$ e números para as quatro matriclasses $[1 ; 2 ; 3 ; 4]$, as dezesseis seçôes possíveis seriam as seguintes:

[A1; A2; A3; A4; B1; B2; B3; B4; C1; C2; C3; C4; D1; D2; D3; D4].

11. Sobre as diferentes possibilidades lógicas de sistemas de descendência, consultar Coelho de Souza (2002).

12. Mesmo que Fortes tenha distinguido entre filiação e descendência, e a esta última tenha permitido "possessóes imateriais", argumentei em outra ocasião que é ainda preciso ter cautela para não lermos o material djeoromitxi em termos de uma simples complementação que a primeira faria sobre a segunda. O problema é imaginarmos que se poderia ter grupos de descendência no sentido que Fortes estabeleceu no ambiente djeromitxi, onde, justamente, a relação com "ancestrais" tem algum rendimento somente até a geração dos avós. A transformação que os Djeoromitxi operariam sobre o conceito de "filiação complementar" é marcada pela dividualidade e por relaçóes figura/fundo: não se trata propriamente de uma complementação a algo já dado, mas de construçóes que ocorrreriam "em paralelo" e que teriam o poder de desestabilizar uma à outra. Essa desestabilização é realizada ao longo das geraçóes e transformaria esses grupos ("de descendência", se quisermos) desde o seu interior, por meio da filiação uterina e da intensa exogamia de patrigrupo ali observada. Para maiores detalhes, ver Soares-Pinto (2014).

13. Essa é justamente a possibilidade que Coelho de Souza (1995) julgou pertinente para os filhos de primos distantes e que, posteriormente, foi descrita por Guerreiro Jr. (2008) para os Kalapalo do Alto Xingu.

14. Overing Kaplan define "afinidade serial" quando dois irmãos podem casar com duas irmãs: "among the Piaroa the alliance process follows a principle which can be described somewhat cumbersomely as 'serial exchange of children by two affines'. The viability of the relationship is correlated with the number of the exchanges. It should be noted that it is the exchange situation itself that is crucial to the establishment of an alliance: there need be no balance in the number of women moving in each direction" (1972:287).

15. Para maiores informações sobre a constituição da chefia djeoromitxi e de povos vizinhos, ver Soares-Pinto (2014).

\section{Referências}

COELHO DE SOUZA, Marcela S. 1995. "Da complexidade do elementar: para uma reconsideração do parentesco xinguano". In: Eduardo Viveiros de Castro (Org.). Antropologia do parentesco: estudos ameríndios. Rio de Janeiro: Editora UFRJ. pp. 121-206. 
2002. O traço e o círculo: o conceito de parentesco entre os Jê e seus antropólogos. Tese de Doutorado, Museu Nacional.

. 2011. "True endogamy or the outcest taboo (for theKĩsêdjê): how kinship (under)determines humans". Trabalho apresentado no Seminário Antropologia da Raposa: Pensando com Roy Wagner, Florianópolis, 8-11 de agosto

FAUSTO, Carlos. 1995. "De primos e sobrinhas: terminologia e aliança entre os Parakanã (Tupi) do Pará”. In: Eduardo Viveiros de Castro (Org.). Antropologia do parentesco: estudos ameríndios. Rio de Janeiro: Editora UFRJ. pp. 61-119.

FORTES, Meyer. 1959. "Descent, filiation and affinity: A rejoinder to Dr. Leach”. Man 59, arts.pp. 309- 331.

1970. Time and social structure and other essays. University of London: The Athlone Press.

GALVÃO, Eduardo. 1960. "Áreas culturais indígenas do Brasil; 1900-1959”. Boletim do Museu Paraense Emilio Goeldi,, Nova Série Antropologia, No. 8, Belém, Brasil, 1960. 41 pp., bibliography, 4 maps. n.p.

GUERREIRO Jr., Antônio. 2008. Parentesco e aliança entre os Kalapalo do Alto Xingu. Dissertação de Mestrado, Universidade Federal de São Carlos.

KAPLAN, Joanna Overing. 1972. "Cognation, endogamy, and teknonymy: the Piaroa example”. Southwestern Journal of Anthropology, 28(3):282-297.

LEA, Vanessa. 1995. "Casa-se do outro lado: um modelo simulado da aliança mebengokre (Jê)". In: Eduardo Viveiros de Castro (Org.). Antropologia do parentesco: estudos amerindios. Rio de Janeiro: Editora UFRJ. pp. 321-359.

LÉVI-STRAUSS, Claude. 1982. As estruturas elementares do parentesco. Petrópolis: Vozes.

LOUNSBURY, Floyd G. 1964. A formal account of the Crow-and Omaha-type kinship terminologies. In: W. H. Goodenough (Ed.). Explorations in cultural anthropology (essays in honor of George Peter Murdock). New York: McGraw-Hill. pp. 351-393.

MALDI, Denise. 1991. "O complexo cultural do marico: sociedades indígenas do Rio Branco, Colorado e Mequens, afluentes do Médio Guaporé". Boletim do Museu Paraense Emilio Goeldi, 7(2):209-269.

MURDOCK, George P. 1965. Social structure. New York: Free Press. Publicado originalmente em 1949.

PARKIN, Robert. 1997. Kinship. An Introduction to Basic Concepts. Oxford: Blackwell. 
RIBEIRO, Eduardo Rivail \& VAN DER VOORT, Hein. 2010. "The inclusion of the Jabutí language family in the Macro-Jê stock". International Journal of American Linguistics, 76(4):517-750.

RIBEIRO, Michela A. 2008. Dicionário djeoromitxi-português: registro da diversidade lingüistica do povo Jabuti. Dissertação de Mestrado, Universidade de Rondônia.

SCHEFFLER, H.W. 1966. "Ancestor worship in anthropology: or, observations on descent and descent groups [and comments reply]". Current Anthropology, 7(5):541-551.

. 1985. "Filiation and affiliation". Man, NS. 20:1-21.

SCHEFFLER, Harold, \& Floyd LOUNSBURY. 1971. A Study in Structural Semantics: the Siriono System of Kinship. Englewood Cliffs, NJ.: Prentice-Hall.

SILVA, Márcio. 2008. "A aliança em questão". In: Rubem Caixeta de Queiroz \& Renarde Freire Nobre (Ed.): Lévi-Strauss: leituras brasileiras. Belo Horizonte: Editora UFMG. pp. 301-324.

SOARES-PINTO, Nicole. 2009. Do poder do sangue e da chicha: os Wajuru do Guaporé (Rondônia). Dissertação de Mestrado, Universidade Federal do Paraná.

. 2012. "Nós somos todos misturados: histórias e parentesco Wayoro (Rondônia)". In: José Pimenta \& Maria Inês Smiljanic (Orgs.). Etnologia indígena e indigenismo. Brasília: Positiva. pp. 159- 184.

. 2014. Entre as teias do Marico: parentes e pajés Djeoromitxi. Tese de Doutorado, Universidade de Brasília.

TRAUTMANN, Thomas \& WHITELEY, Peter (orgs.). 2012. Crow-Omaha: new light on a classic problem of kinship analysis. Tucson: The University of Arizona Press.

TAX, Sol. 1955. “Some problems of social organization”. In: Fred Eggan (org.). Social anthropology of North American tribes.Chicago: The University of Chicago Press. pp. $3-32$.

VIVEIROS DE CASTRO, Eduardo. 1996. "Ambos os três: sobre algumas distinçóes tipológicas e seu significado estrutural na Teoria do Parentesco". Anuário Antropológico, 95:9-91.

. 2002. "O problema da afinidade na Amazônia" In: . A inconstância da alma selvagem. São Paulo: Cosac Naify. pp. 87-180.

VIVEIROS DE CASTRO, Eduardo \& FAUSTO, Carlos. 1993. "La puissance et l'acte: la parenté dans les basses terres Sud-Americaine”. L'Homme, 33(2-4):141-170.

YOUNG, Philip. 1970. "A structural model of Ngawbe marriage". Ethnology, 9(1):85-95. 


\section{Resumo}

Este artigo apresenta um modelo do sistema de parentesco djeoromitxi, povo de língua Macro-Gê habitante do sudoeste amazônico (Terra Indígena Rio Guaporé/Rondônia). Sua descrição incluirá a terminologia, que será relacionada a um tipo de cruzamento e aliança, na medida em que essa terminologia codifica os cônjuges que são preferenciais (aos quais se aplica o termo wirá), mas não correspondem aos primos cruzados. Veremos, assim, que tipo de cruzamento é concernente ao modelo djeoromitxi de parentesco, e quais são as características de seu sistema de aliança.

\section{Abstract}

This article presents a model of Djeoromitxí's kinship system, Macro-Ge speakers, inhabitants of the southwestern Amazonia (Rio Guaporé Indigenous Land/Rondônia). The description of the Djeoromitxí's kinship system include the terminology, which is related to a type of crossing and alliance, to the extent that this terminology encodes spouses (to whom the term wirá applies) who, though preferential, do not correspond to the cross-cousin. We will see, then, what kind of crossing concerns the Djeoromitxí's kinship model, and the features of its alliance system.

Palavras-chave: djeoromitxi, Keywords: Djeoromitxí, kinship, parentesco, terminologia, cruzamento, terminology, crossing, aliance. aliança. 